\title{
Efficient regeneration and improved sonication-assisted Agrobacterium transformation (SAAT) method for Catharanthus roseus
}

\author{
Pravej Alam ${ }^{1,2}$ - Zainul Abdeen Khan ${ }^{2}$ Malik Zainul Abdin ${ }^{3} \cdot$ Jawaid A. Khan $^{2}$ • \\ Parvaiz Ahmad $^{4,5} \cdot$ Shereen F. Elkholy ${ }^{1,6} \cdot$ Mahmoud A. Sharaf-Eldin ${ }^{1,7}$
}

Received: 28 September 2016/Accepted: 23 December 2016/Published online: 11 April 2017

(c) The Author(s) 2017. This article is an open access publication

\begin{abstract}
Catharanthus roseus is an important medicinal plant known for its pharmacological qualities such as antimicrobial, anticancerous, antifeedant, antisterility, antidiabetic activities. More than 130 bioactive compounds like vinblastine, vindoline and vincristine have been synthesized in this plant. Extensive studies have been carried out for optimization regeneration and transformation protocols. Most of the protocol described are laborious and time-consuming. Due to sophisticated protocol of regeneration and genetic transformation, the production of these bioactive molecules is less and not feasible to be commercialized worldwide. Here we have optimized the efficient protocol for regeneration and transformation to minimize the time scale and enhance the transformation
\end{abstract}

Pravej Alam

alamprez@gmail.com

1 Sara Alghonaim Research Chair (SRC), Biology Department, College of Science and Humanities, Prince Sattam bin Abdulaziz University (PSAU), Alkharj 11942, Kingdom of Saudi Arabia

2 Department of Biosciences, Faculty of Natural Sciences, Jamia Millia Islamia, New Delhi 110025, India

3 Department of Biotechnology, Faculty of Science, Centre for Transgenic Plant Development, Jamia Hamdard, New Delhi 110062, India

4 Department of Botany and Microbiology, Faculty of Science, King Saud University, Riyadh 11451, Saudi Arabia

5 Department of Botany, S.P. College, Srinagar 190001, Jammu and Kashmir, India

6 Plant Transformation and Biopharmaceuticals Lab, Agricultural Genetic Engineering Research Institute (AGERI), Agricultural Research Centre (ARC), Giza, Egypt

7 Department of Medicinal and Aromatic Plants Research, National Research Centre (NRC), Cairo 12622, Egypt frequency through Agrobacterium and sonication-assisted transformation (SAAT) method. In this study, hypocotyl explants responded best for maximal production of transformed shoots. The callus percentage were recorded $52 \%$ with $1.0 \mathrm{mg} \mathrm{L}^{-1}$ (BAP) and $0.5 \mathrm{mg} \mathrm{L}^{-1}$ (NAA) while $80 \%$ shoot percentage obtained with $4.0 \mathrm{mg} \mathrm{L}^{-1}$ (BAP) and $0.05 \mathrm{mg} \mathrm{L}^{-1}$ (NAA). The microscopic studies revealed that the expression of GFP was clearly localized in leaf tissue of the $C$. roseus after transformation of pRepGFP0029 construct. Consequently, transformation efficiency was revealed on the basis of GFP localization. The transformation efficiency of SAAT method was $6.0 \%$ comparable to $3.5 \%$ as conventional method. Further, PCR analysis confirmed the integration of the $n p t I I$ gene in the transformed plantlets of $C$. roseus.

Keywords Catharanthus roseus - Internode - Hypocotyl · Regeneration · SAAT · BAP · NAA · Agrobacterium · GFP

\section{Introduction}

Catharanthus roseus (L.) is a dicotyledonous medicinal plant naturalized in many countries like India, Saudi Arabia, South Africa, USA, Australia and most of the European region. The plant is cultivated worldwide for an ornamental purpose (Mujib et al. 2014). The important anticancer pharmaceuticals, vinblastine and vincristine, are also produced in very small quantities within the aerial parts of the Catharanthus roseus. The high cost of isolating the drugs has led to research efforts to increase the alkaloid content of $C$. roseus cell cultures, tissue cultures and seedlings.

The metabolic engineering of $C$. roseus strives is used to overcome the strict regulation of the alkaloid biosynthetic 
pathway. The alkaloid biosynthesis pathway in C. roseus is very complex and produces approximately 130 different alkaloids (Morgan et al. 2000). The high pharmaceutical cost associated with vinblastine and vincristine is a result of the very low quantities in which they are produced in planta and the isolation of these compounds from extracts. A total of $1000 \mathrm{~kg}$ of leaf and stem materials are required to produce $1 \mathrm{~g}$ and $20 \mathrm{mg}$ vinblastine and vincrestine, respectively, (Facchini and De Luca 2008). Biosynthesis of these compounds occurs in five different subcellular compartments and three or more different cell types. It requires at least 35 intermediates and 30 enzymatic steps for biosynthesis of vinblastine and vincristine (Schröder et al. 1999; Lange et al. 2000; Morgan et al. 2000; Peebles et al. 2009 ). Due to low content ( $\sim 0.0003 \%$ ) of vinblastine and vincristine and expensive cost, the drugs could not be commercialized in global market. The straight chemical synthesis is not feasible due to chemical structure complexity and stereochemistry (Lange et al. 2000). Several investigators have carried out biotechnological efforts at in vitro level to elucidate the biosynthetic pathway and its genes to enhance the production of these drugs by genetic modulation of plant (van Der Heijden et al. 2004; Liscombe et al. 2010). Due to ineffective transformation and regeneration protocols, the rate of transformation is quite low. Therefore, we have developed an efficient regeneration and sonication-assisted Agrobacterium tumefaciensmediated transformation method for C. roseus.

\section{Materials and methods}

\section{Plant material and seed germination}

Seeds of Catharanthus roseus were procured from Herbal Garden, Jamia Hamdard, New Delhi, India. The seeds were sterilized with mercuric chloride $(0.1 \%)$ for $2 \mathrm{~min}$, followed by washing with double-distilled sterile water. Thereafter, sterilized seeds were cultured on MS basal medium containing sucrose $(3.0 \% \mathrm{w} / \mathrm{v})$ and agar $(0.8 \%$ w/v) for germination at $\mathrm{pH} 5.8$ and autoclaved for 1 bar pressure at $20 \mathrm{~min}$. The seedlings of $C$. roseus were maintained at $25 \pm 2{ }^{\circ} \mathrm{C}$ under a $16 \mathrm{~h}$ (hour) light and $8 \mathrm{~h}$ dark regimes.

\section{Optimization of regeneration protocol for Catharanthus roseus}

Small young in vitro raised plantlets were collected from 10 days old healthy Catharanthus roseus plants, cut into 1-1.5 cm hypocotyl and 3-5 $\mathrm{mm}$ internode long in size. MS medium (Murashige and Skoog 1962) was supplemented with various plant growth regulators. NAA (naphthalene acetic acid) and BAP (6-benzylaminopurin) in combination with different concentration have been used for callus and shoot induction (Tables 1,2). There were 17 treatments of BAP and NAA used for callus induction for the explants; casein hydrolysate $\left(150 \mathrm{mg} \mathrm{L}^{-1}\right)$, sucrose $(3 \%)$, proline $\left(250 \mathrm{mg} \mathrm{L}^{-1}\right)$ and agar $0.8 \%$ were inoculated in callus induction medium. The cultures were incubated under fluorescent lights with $2300 \mathrm{l} \times$ for $16 \mathrm{~h}$ at a temperature of $25 \pm 2{ }^{\circ} \mathrm{C}$.

In callus induction both hypocotyl and internode segments were used, but only hypocotyl induced the better callus growth while the internode generated moderate type of callus. After 10 days of incubation, the calli of hypocotyl explants were further cultured on shoot induction medium. We have optimized the 36 treatments for shoot induction medium (SIM) using the various concentration and combinations of naphthalene acetic acid (NAA) and 6-benzylaminopurin (BAP). After 15 days of culture on SIM and optimization of the best shoot induction frequency, the clusters of shoots were excised from the base of the callus and cultured on shoot elongation medium (MS basal). After two weeks, the apical dominance was observed in shoots with many plantlets. The shoots were thereafter cultured on rooting media with varying concentration of NAA $\left(0.1-1.0 \mathrm{mg} \mathrm{L}^{-1}\right)$ and IBA (0.1-1.0 $\left.\mathrm{mg} \mathrm{L}^{-1}\right)$ in MS medium having sucrose $(3 \% \mathrm{w} / \mathrm{v})$, agar $(0.8 \% \mathrm{w} / \mathrm{v})$, proline $\left(250 \mathrm{mg} \mathrm{L}^{-1}\right)$ and casein hydrolysate $\left(150 \mathrm{mg} \mathrm{L}^{-1}\right)$.

Table 1 Effect of different concentrations of BAP sand NAA on $\%$ callus induction in the hypocotyl explants of C. roseus

\begin{tabular}{lll}
\hline Growth regulator $\left(\mathrm{mg} \mathrm{L}^{-1}\right)$ & \multicolumn{1}{l}{ Callus formation $(\%)$} \\
\hline BAP & NAA & \\
\hline 0.0 & - & - \\
0.1 & - & - \\
0.5 & - & - \\
1.0 & - & - \\
- & 0.0 & - \\
- & 0.1 & $1.00 \pm 0.35$ \\
- & 0.5 & $1.50 \pm 0.57$ \\
- & 1.0 & $2.0 \pm 0.43$ \\
0.1 & 0.5 & $6.66 \pm 1.55$ \\
0.1 & 1.0 & $10.66 \pm 1.52$ \\
0.1 & 1.5 & $3.00 \pm 0.51$ \\
0.5 & 0.5 & $4.33 \pm 0.58$ \\
0.5 & 1.0 & $23.00 \pm 2.35$ \\
0.5 & 1.5 & $25.66 \pm 0.57$ \\
1.0 & 0.5 & $52.00 \pm 2.00$ \\
1.0 & 1.0 & $32.66 \pm 2.08$ \\
1.0 & 1.5 & $24.66 \pm 2.51$ \\
\hline
\end{tabular}

Each value is the mean \pm standard error $(n=5)$ 
Table 2 Effect of various concentrations of BAP and NAA on the shoot induction from hypocotyls explant of $C$. roseus

\begin{tabular}{|c|c|c|c|c|}
\hline Treatments & $\begin{array}{l}\text { BAP } \\
\left(\mathrm{mg} \mathrm{L}^{-1}\right)\end{array}$ & $\begin{array}{l}\text { NAA } \\
\left(\mathrm{mg} \mathrm{L}^{-1}\right)\end{array}$ & $\begin{array}{l}\text { Shoot } \\
\text { induction }(\%)\end{array}$ & $\begin{array}{l}\text { No. of shoots per } \\
\text { explants }\end{array}$ \\
\hline MS0 & - & - & - & - \\
\hline MS1 & 1.0 & - & - & - \\
\hline MS2 & 1.5 & - & - & - \\
\hline MS3 & 2.5 & - & - & - \\
\hline MS4 & 2.0 & - & - & - \\
\hline MS5 & 3.0 & & & - \\
\hline MS6 & 4.0 & & & - \\
\hline MS7 & - & 0.01 & - & - \\
\hline MS8 & - & 0.02 & - & - \\
\hline MS9 & - & 0.03 & - & - \\
\hline MS10 & - & 0.04 & - & - \\
\hline MS11 & - & 0.05 & - & - \\
\hline MS12 & 1.0 & 0.01 & - & - \\
\hline MS13 & 1.0 & 0.02 & - & - \\
\hline MS14 & 1.0 & 0.03 & - & - \\
\hline MS15 & 1.0 & 0.04 & - & - \\
\hline MS16 & 1.0 & 0.05 & - & - \\
\hline MS17 & 2.0 & 0.01 & - & - \\
\hline MS18 & 2.0 & 0.02 & - & - \\
\hline MS19 & 2.0 & 0.03 & - & - \\
\hline MS20 & 2.0 & 0.04 & - & - \\
\hline MS21 & 2.0 & 0.05 & - & - \\
\hline MS22 & 3.0 & 0.01 & - & - \\
\hline MS23 & 3.0 & 0.02 & + & - \\
\hline MS24 & 3.0 & 0.03 & + & - \\
\hline MS25 & 3.0 & 0.04 & ++ & - \\
\hline MS26 & 3.0 & 0.05 & ++ & - \\
\hline MS27 & 4.0 & 0.1 & ++ & - \\
\hline MS28 & 4.0 & 0.02 & 45 & $12 \pm 0.55$ \\
\hline MS29 & 4.0 & 0.03 & 53 & $19 \pm 2.15$ \\
\hline MS30 & 4.0 & 0.04 & 65 & $25 \pm 2.15$ \\
\hline MS31 & 4.0 & 0.05 & 80 & $35 \pm 0.70$ \\
\hline MS32 & 5.0 & 0.1 & 40 & $15 \pm 0.37$ \\
\hline MS33 & 5.0 & 0.02 & 35 & $12 \pm 0.52$ \\
\hline MS34 & 5.0 & 0.03 & 20 & $10 \pm 0.40$ \\
\hline MS35 & 5.0 & 0.04 & 15 & $9.0 \pm 0.55$ \\
\hline MS36 & 5.0 & 0.05 & 12 & $6.0 \pm 0.65$ \\
\hline
\end{tabular}

Each value is the mean \pm standard error $(n=5)$

\section{Determinition of optimal concentration of kanamycin for $C$. roseus transformants}

To examine the transformed shoots from hypocotyl explants on shoot induction medium, a selection agent (antibiotics) was needed to check the false and putative transformants, hypocotyl explants were cultured on MS medium, containing various concentrations of kanamycin $\left(5,10,15,20,30,40,5060,70,80,100 \mathrm{mg} \mathrm{L}^{-1}\right)$. The calli were induced only in those have transformed and adventitious shoots thereafter were counted with respect to transformation frequencies on shoot induction medium.

\section{Transformation of $C$. roseus hypocotyl explants}

Conventional and sonication-assisted Agrobacteriummediated transformation (SAAT)

Agrobacterium strain LBA4404 harbouring GFP gene construct cloned into pGreen0029 (pRepGFP0029) tagged with newly identified strong constitutive promoter (Fig. 1, Khan et al. 2015) was obtained from Plant virology laboratory, Department of Biosciences, Jamia Millia Islamia, New Delhi, India. Agrobacterium tumefaciens strain LBA4404 harbouring pRepGFP0029 along with pSoup helper plasmid, culture in $50 \mathrm{~mL}$ of YEB (yeast extract broth) medium with Kan (kanamycin, $50 \mathrm{mg} \mathrm{L}^{-1}$ ) and Rif (rifampicin $10 \mathrm{mg} \mathrm{L}^{-1}$ ) at $27^{\circ} \mathrm{C}$ until an $\mathrm{OD}_{600} \mathrm{~nm}$ reached 0.8 following the method of Khan et al. (2015). Overnight culture was centrifuged and pellet was re-suspended in $100 \mathrm{~mL}$ MS liquid with $3 \%$ sucrose (w/v). For conventional method, hypocotyl explants were thereafter immersed in Agrobacterium tumefaciens LBA4404 culture $\left(\mathrm{OD}_{600} 0.8\right)$ for $1 \mathrm{~h}$ at normal room temperature with a slight shaking. After $1 \mathrm{~h}$ of Agrobacterium infection, the hypocotyl explants were evoked from medium and blot off on sterile tissue paper. Further, infected explants were cultured on co-culture medium [MS salt, sucrose (3\%), proline $\left(250 \mathrm{mg} \mathrm{L}^{-1}\right)$, casein hydolysate $\left(150 \mathrm{mg} \mathrm{L}^{-1}\right)$ and agar (0.8\%)]. at $28{ }^{\circ} \mathrm{C}$ in the dark for 4 days.

Similarly, overnight Agrobacterium culture previously mixed in MS liquid medium was again treated with hypocotyl explants under centre of bath in ultra-sonication unit (ImecoUltrasonics, India) for $10 \mathrm{~min}$ in

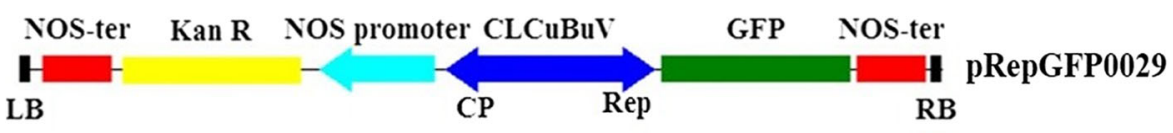

Fig. 1 Schematic representation of the expression vector (pGreen0029) containing green fluorescent protein tagged with $\mathrm{CLCuBuV}$ promoter. $C P$ coat protein, Rep replication initiation protein, $C L C u B u V$ cotton leaf curl Burewala virus, $L B$ left-border sequence of T-DNA, $R B$ right-border sequence of T-DNA, GFP green fluorescent protein, Kan $R$ Kanamycin resistance gene 
microcentrifuge tubes. Hypocotyl explants of $C$. roseus were removed from micro centrifuge tubes, placed on sterile tissue paper to blot off the excess bacteria on the surface of the explants and cultured on same co-cultivation medium [MS salt, sucrose $(3 \%)$, Proline $\left(250 \mathrm{mg} \mathrm{L}^{-1}\right)$, casein hydolysate $\left(150 \mathrm{mg} \mathrm{L}^{-1}\right)$ and agar $\left.(0.8 \%)\right]$ for 4 days. After 4 days of co-cultivation, hypocotyl explants were washed with double-distilled sterile water and blot dried with sterile tissue paper. After proper washing with sterile water, hypocotyl explants were further washed with cefotaxime $\left(500 \mathrm{mg} \mathrm{L}^{-1}\right)$ for $10 \mathrm{~min}$ to kill the excess growth of bacteria. This step was repeated twice and finally explants were washed with sterile water. Although the regeneration of the shoot was not induced directly, the explants were first cultured on pre-standardized callus and shoot induction medium in a sequential manner (Tables 1, 2). After proper attaining of cultured shoots on shoot induction selection medium (SISM), the induced shoots were cultured in pre-optimized root induction medium with selection agent (Tables 1,2). To facilitate the optimization of the method of conventional and SAAT-based transformation methods of hypocotyl of $C$. roseus, several factors like pre-culture of explants, Agrobacterium density, infection time and co-cultivation period have been studied for achieving a high rate of transformants. The transformation frequency was counted on the basis of GFP localization and nptII gene integration of transformants grown on SISM using confocal microscopy and PCR assays.

The transformation efficiency was calculated according to the following formula:

Transformation efficiency $(\%)$

$=\frac{\text { Number of GFP positive plants }}{\text { Number of explants inoculated with Agrobacterium }} \times 100$.

\section{GFP Localization and PCR analysis of transformed leaves of $C$. roseus}

The localization of green fluorescent protein (GFP) in the transformed leaves of $C$. roseus was carried out using inverted florescent microscope (Motic) and confocal laser scanning microscope (40.0X1.15OIL, Leica Microsystems, Germany). To observe the GFP in transformed leaves of $C$. roseus, the AOTF (Acousto-Optical Tunable Filter) of $488 \mathrm{~nm}$ (at 40\%) was used and the fluorescence emission collected between 501 and $598 \mathrm{~nm}$ as described earlier by Khan et al. (2015).

Genomic DNA from transformed leaves of $C$. roseus was extracted by employing the method of Doyle and Doyle (1990). The presence of nptII transgene signals in plant tissue was confirmed by PCR amplification using the specific primers set (forward 5'ATGCCCGATCGAGCTC AAGT3' and reverse 5'TCGTCTGGCTGACTTTCGTCA
$\mathrm{TAA}^{\prime}{ }^{\prime}$. The $\mathrm{PCR}$ reaction mixture was carried out in $100 \mu \mathrm{L}$ eppendorf tubes in Gstorm thermal cycler (Germany). The reaction mixture of total volume $25 \mu \mathrm{L}$ contained 2X Taq polymerase assay buffer, $2.5 \mathrm{mM}$ dNTP, $100 \mathrm{ng}$ forward and reverse primers, 3UTaq DNA polymerase and template DNA (100 ng) with the following parameters: initial denaturation $94^{\circ} \mathrm{C}, 5 \mathrm{~min}$; followed by 35 cycles; denaturation $94^{\circ} \mathrm{C}, 1.0 \mathrm{~min}$; ; annealing $55^{\circ} \mathrm{C}$, $1.0 \mathrm{~min}$; elongation $72{ }^{\circ} \mathrm{C}, 2.0 \mathrm{~min}$ with final extension $72{ }^{\circ} \mathrm{C}, 5$ min.. PCR products were resolved on $1.0 \%$ agarose gel stained with ethidium bromide and visualized in UVI gel documentation system.

\section{Statistical analyses}

All experiments were directed on the basis of three replicates using one-way analysis of variance (ANOVA) followed by DMRT (Duncan's multiple range) by using the SPSS statistical software. The values are mean \pm SE for three samples in each group were studied. $P$ values at $\leq 0.05$ were measured as significant.

\section{Results and discussion}

\section{Establishment of in vitro regeneration for $C$. roseus}

The seedlings of $C$. roseus raised aseptically from seeds were used as a source of explants. The hypocotyl (7 days) and internode (20 days) explants were designated and cultured on MS (Murashige and Skoog 1962) medium augmented with different plant growth regulators like naphthalene acetic acid (NAA) and 6-benzyl amino purine (BAP), either alone or in combinations of callus and shoot induction media (Tables 1, 2). The cultures were maintained at white fluorescent light $(2300 \mathrm{l} \times)$ for $16 \mathrm{~h}$ with $25 \pm 2{ }^{\circ} \mathrm{C}$.

\section{Effect of BAP and NAA on callus induction}

In order to study the effect of BAP and NAA on induction and growth of callus from the cultured hypocotyl and internodal explants of $C$. roseus, different concentrationsof BAP and NAA, along with proline $\left(250 \mathrm{mg} \mathrm{L}^{-1}\right)$ and casein hydrolysate $\left(150 \mathrm{mg} \mathrm{L}^{-1}\right)$ were tested singly as well as in combinations.

The callus induction responses of the hypocotyl explants ranged from $1.00 \pm 0.35$ to $52.00 \pm 2.00$ with the ranging concentration of BAP and NAA. But the internode explants showed moderate response on callus development with different combinations and concentration of BAP and NAA (Table 1). Single BAP or NAA treatments did not exhibit any significant response, as only small callus was initiated 
within 4 weeks of inoculation (Table 1). However, the treatment of cytokinins and auxins at various concentrations and combinations exhibited significant response in terms of callus induction, but with varying degree of callus growth. Among the various combinations tested, the medium comprised of MS with $1.0 \mathrm{mg} \mathrm{L}^{-1} \mathrm{BAP}$ and $0.5 \mathrm{mg} \mathrm{L}^{-1}$ NAA proved to be the best with $52.00 \pm 2.00 \%$ callus formation with hypocotyl explants (Table 1). On this medium, callus initiation was started from the edge of the explants after 4 days of inoculation. The responses of calli initiation and growth were decreased as the concentration of both BAP and NAA was dropped.

\section{Multiple shoot induction, elongation and rooting}

The hypocotyl explants were further cultured on shoot induction medium (SIM) containing various combinations of BAP and NAA along with proline $\left(250 \mathrm{mg} \mathrm{L}^{-1}\right)$, casein hydrolysate $\left(150 \mathrm{mg} \mathrm{L}^{-1}\right)$ and sucrose (3\%; MS basal medium contains BAP or NAA alone did not respond to morphogenesis (Table 2), whereas on shoot induction medium comprised of MS with various concentrations of BAP and NAA, they exhibited shoot induction on some selective concentration (Table 2). The highest concentration of BAP with a very low concentration of NAA was found to be quite beneficial for shoot induction. The MS medium with BAP (4.0 $\left.\mathrm{mg} \mathrm{L}^{-1}\right)$ and NAA $\left(0.05 \mathrm{mg} \mathrm{L}^{-1}\right)$ evoked maximum response $35.0 \pm 0.7$ (80\%) shoots per explant after 5 weeks of culture period. The shoot initiation was started after 15 days of callus culture. On lowering or increasing the concentration of either of the PGRs, the shoot regeneration frequency was declined (Table 2).

As the regenerated shoots on the optimal medium for shoot induction (MS, $4.0 \mathrm{mg} \mathrm{L}^{-1} \mathrm{BAP}, 0.05 \mathrm{mg} \mathrm{L}^{-1} \mathrm{NAA}$, along with $250 \mathrm{mg} \mathrm{L}^{-1}$ proline, $150 \mathrm{mg} \mathrm{L}^{-1}$ casein hydrolysate and $3 \%$ sucrose) could not attain a suitable length to be utilized for rooting, the clusters of developed shoots were excised and cultured on growth regulator-free MS medium [MS basal along with proline $\left(250 \mathrm{mg} \mathrm{L}^{-1}\right)$, casein hydrolysate $\left(150 \mathrm{mg} \mathrm{L}^{-1}\right)$ and sucrose $\left.(3 \%)\right]$. On this medium,

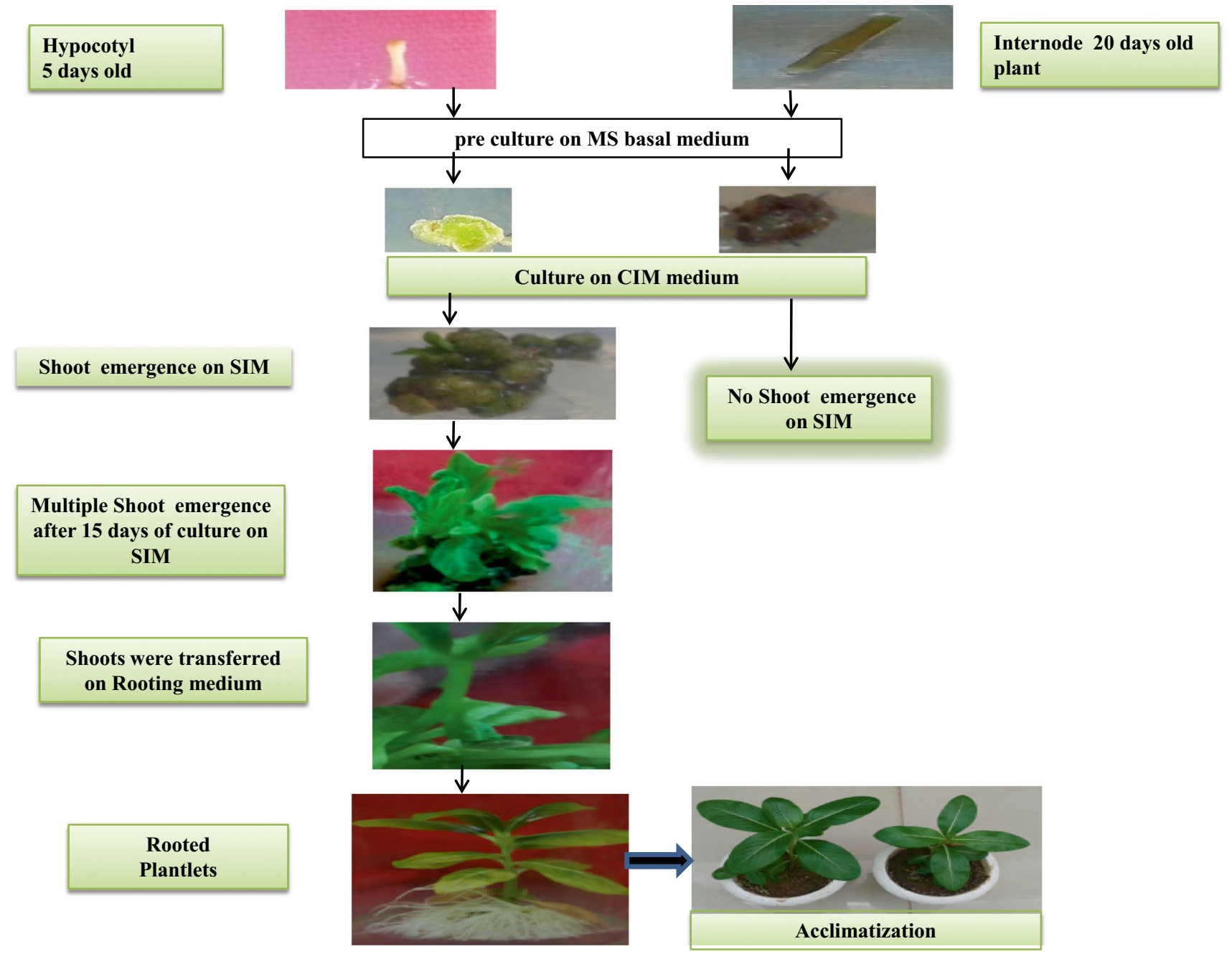

Fig. 2 Stages of regenertion of C. roseus though internodal and hypocotyl segments 
elongation in the shoots accelerated after 2 weeks of culture, attaining a suitable length of $1.5 \mathrm{~cm}$ within 4 weeks (Fig. 2). The microshoots of $C$. roseus (size $2.0 \mathrm{~cm}$ ) were excised from the shoot clusters and cultured on rooting medium to get complete plantlets.

The rooting medium was comprised of MS basal medium, with various concentrations of NAA or IBA $(0.1,0.5$ and $\left.1.0 \mathrm{mg} \mathrm{L}^{-1}\right)$ along with casein hydolysate $\left(150 \mathrm{mg} \mathrm{L}^{-1}\right)$ and proline $\left(250 \mathrm{mg} \mathrm{L}^{-1}\right)$. IBA proved to be the best at $1.0 \mathrm{mg} \mathrm{L}^{-1}$ concentration and recorded $30.0 \pm 0.36$ roots per shoot were produced in $100 \%$ cultures in 5 weeks of culture period. On this rooting medium [MS + IBA (1.0 $\left.\mathrm{mg} \mathrm{L}^{-1}\right)$ ], the root induction was observed after 10 days of planting. While in NAA-supplemented medium, higher concentration of the growth regulator $\left(1.0 \mathrm{mg} \mathrm{L}^{-1}\right)$ has induced only $16.5 \pm 0.23$ roots/shoot (Table 3 ).

The morphogenic comebacks of micropropagated plant are mainly affected by the media component (s) and plant growth regulator concentration. In order to optimize the suitable regeneration frequency of $C$. roseus and to increase the possibility of rate of transformants, we therefore, optimized 17 and 36 media treatment (Tables 1, 4) for callus and shoot to check the regeneration ability of the hypocotyl and internodal explants of $C$. roseus. Hundred explants were inoculated on each treatment of MS medium with variousconcentration (s) of BAP and NAA (Tables 1, 4). Only hypocotyl explants were responding for good callus

Table 3 Effect of growth regulators (NAA and IBA) on rooting of in vitro regenerated shoots of $C$. roseus

\begin{tabular}{llc}
\hline Growth regulators & Concentration $(\mathrm{mg} / \mathrm{L})$ & No. of roots/plantlet \\
\hline IBA & 0.1 & $5.0 \pm 0.30$ \\
& 0.5 & $12.3 \pm 0.25$ \\
& 1.0 & $30.0 \pm 0.36$ \\
NAA & 0.1 & $4.0 \pm 0.41$ \\
& 0.5 & $10.5 \pm 0.52$ \\
& 1.0 & $16.5 \pm 0.23$ \\
\hline
\end{tabular}

Each value is the mean \pm standard error $(n=5)$

Table 4 Selection of number of transformants on shoot induction selection medium (SISM) containing kanamycin $\left(\operatorname{Kan}^{r}\right)$ and GFP positive shoots after co-cultivation of $C$. roseus hypocotyl explants infected with Agrobacterium tumefaciens LBA4404

\begin{tabular}{llllll}
\hline \multirow{2}{*}{ No. of explants } & $\operatorname{Kan}^{\mathrm{r}}$ & & & \multicolumn{2}{l}{ GFP } \\
\cline { 2 - 3 } \cline { 5 - 6 } \cline { 5 - 6 } & SAAT & Conventional & & SAAT & Conventional \\
\hline 50 & $4 \pm 0.43$ & $2 \pm 0.33$ & & $3 \pm 0.44$ & $1 \pm 0.32$ \\
50 & $3 \pm 0.21$ & $2 \pm 0.3$ & & $3 \pm 0.44$ & $2 \pm 0.32$ \\
50 & $4 \pm 0.44$ & $3 \pm 0.18$ & & $4 \pm 0.4$ & $3 \pm 0.31$ \\
50 & $3 \pm 0.22$ & $1 \pm 0.22$ & & $2 \pm 0.11$ & $1 \pm 0.32$
\end{tabular}

Each value is the mean \pm standard error $(n=3)$ induction while for intermodal segment poorly developed calli were obtained (Fig. 2). On the basis of growth of calli, we have further cultured the calli of hypocotyl on shoot induction medium (SIM). The inducing of a proliferated calli of the explants showed profound changes in the developmental stages of the tissue and hence resulted in alteration in the basic architecture of cell and tissues for quiescent or fully differentiated cells. One of the most influencing factors in multiple shoot induction of hypocotyl explants is the modulation of endogenous auxin to cytokinin balance. Morphogenic responses thus exhibited in the form of shoots or roots correlated with the specific auxin and cytokinin ratio (Bennici et al. 1988; Thorpe 2006; Chawla and Wenzel 1987). In the present study, we have found that BAP at $4.0 \mathrm{mg} \mathrm{L}^{-1}$ and NAA $0.05 \mathrm{mg} \mathrm{L}^{-1}$ were considered the optimal concentrations to obtain maximum shoot for the hypocotyl explants of $C$. roseus. Increasing BAP and NAA concentrations beyond optimal level have shown a negative effect and the exhibited shoot get stunted in nature with the reduction in number of shoots (Table 2). These findings are in consonance with the results obtained earlier in Erigeron breviscapus (Liu et al. 2008), Dioscorea nipponica (Chen et al. 2007), Sida cordifolia (Sivanesan and Jeong 2007), Aloysia polystachya (Burdyn et al. 2006), Pogostemon heyneanus (Hembrom et al. 2006) and Psoralea corylifolia (Faisal and Anis 2006). Based on the findings, it could be stated that the BAP and NAA ensure in vitro regeneration of shoots from hypocotyl explants and synergism of BAP and NAA in appropriate concentration is promising for $C$. roseus micropropagation.

\section{Genetic transformation of $C$. roseus}

The Agrobacterium-mediated transformation depends upon several parameters for generating the transformed lines of C. rosues. In this method, the lethal dose of kanamycin required for effective selection of transformed hypocotyl explants was determined by the culturing explants on MS basal medium containing various concentrations of kanamycin (0-100 $\mathrm{mg} \mathrm{L}^{-1}$ ). Hypocotyl explants were cultured on shoot induction medium (SIM) for 4-5 days before they were transferred to the same medium containing various concentrations of kanamycin (SISM). There was an enormous growth of callus induced in control hypocotyl explants on the medium without kanamycin. No callus or shoot responded on the MS medium containing $40 \mathrm{mg} \mathrm{L}^{-1}$ or higher concentration of kanamycin. Therefore, selection of kanamycin at $40 \mathrm{mg} \mathrm{L}^{-1}$ was used after co-cultivation and maintained till the callus and shoots were obtained. Kanamycin at $40 \mathrm{mg} \mathrm{L}^{-1}$ resulted in the death of more than $80 \%$ hypocotyl explants; therefore, this concentration was selected as an optimal concentration for selection of transformed lines (data not shown). 
Transformation rate increment through pre-culture and co-cultivation

To determine the high rate of transformation frequency, explants were pre-cultured for 1-7 days and the numbers of transformed explants were recorded. Pre-culture of explants in tolerable situations prior to Agrobacterium infection may improve the rate of transformation with increasing the cells number and competent for transgene insertion (Husaini 2009; Alam et al. 2014) Several investigations used pre-culture period of 3-10 days for different kinds of explants to adjust the rate of transformation in the regeneration media before Agrobacterium infection (Husaini 2009). Pre-culturing explants for 6 days on MS basal medium with proline $\left(250 \mathrm{mg} \mathrm{L}^{-1}\right)$ and casein hydolysate $\left(150 \mathrm{mg} \mathrm{L}^{-1}\right)$ was a prerequisite for the efficient transformation (76\%) and helps in regeneration of explants with Agrobacterium tumefaciens. The use of proline $\left(250 \mathrm{mg} \mathrm{L}^{-1}\right)$ and casein hydolysate $\left(150 \mathrm{mg} \mathrm{L}^{-1}\right)$ in preculture medium functions as osmoprotectant and absorbent of extra salt and saves the explants from death during transformation and regeneration. Those explants which were not treated with pre-culture showed less transformation efficiency (20) on 6 days. In contrast, pre-cultured explants showed improved transformation rates to $76 \%$ (Fig. 3). It was due to the expansion of cell size in term of cell elongation and cell division which was more able to withstand bacterial treatment (Kiani et al. 2014).

Moreover, due to growth, the selectively dividing cells can be more easily transformed. Hypocotyl explants that had not been pre-cultured remained small in size (about $1.0 \mathrm{~cm}^{2}$ compared to $1.5 \mathrm{~cm}^{2}$ for pre-cultured explants) and were severely affected by bacterial treatment.

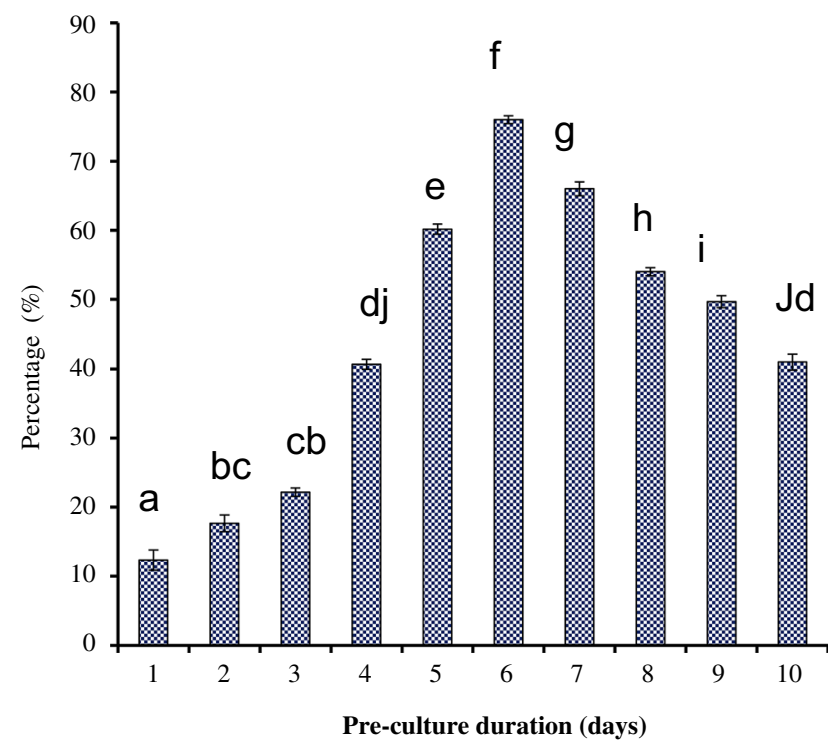

Fig. 3 Influence of pre-culture duration on rate of transformation in C. roseus

\section{Effect of co-cultivation duration on transformation}

The transformation experiment was carried out to check the efficacy of Agrobacterium density, infection time and cocultivation time period. In this study, we have randomly selected 30-min infection time of Agrobacterium and inoculum density of $0.6 \mathrm{OD}_{600} \mathrm{~nm}$ of LBA4404 for $C$. roseus. Previous studies have shown that co-cultivation of explants was essential factor to achieve the maximal transformation rates with Agrobacterium tumefaciens in different plant species (Alam and Abdin 2011; Husaini 2009; Alam et al. 2014). On the basis of previous studies, therefore, we augmented co-cultivation period of hypocotyls explants with A. tumefaciens for 1, 2, 3 and 4 days (d). Furthermore, the co-cultivation period was assayed in the 2 days in dark at $27{ }^{\circ} \mathrm{C}$ in co-cultivation medium containing MS basal with proline $\left(250 \mathrm{mg} \mathrm{L}^{-1}\right)$ and casein hydolysate $\left(150 \mathrm{mg} \mathrm{L}^{-1}\right)$ which leads to higher rates of transformation as compared to the number of days of cocultivation (Fig. 4). If the optical density of bacterial culture is more than 0.8 and co-cultivation period $\geq 3-4$ days, the explants had more overgrowth of bacteria on the surface and leaching had been started. Throughout co-cultivation period, it is noted that an excessive number of bacterial growth caused stress on explants cells and inhibits the regeneration potential. Similarly, the lower number of bacteria $\left(\mathrm{OD}_{600} \leq 0.8\right)$ minimized the rate of recurrence of Transfer DNA in plant cells (Montoro et al. 2003). In this study, 6-day-old hypocotyl explants produced sophisticated number of transformed shoots through callus culture. By increasing the bacterial optical density and time of infection (beyond $30 \mathrm{~min}$ in conventional and $10 \mathrm{~min}$ in SAAT), explants showed blackening and were dead after some time of co-cultivation, due to excessive growth of bacteria. Increasing the co-cultivation duration may

a

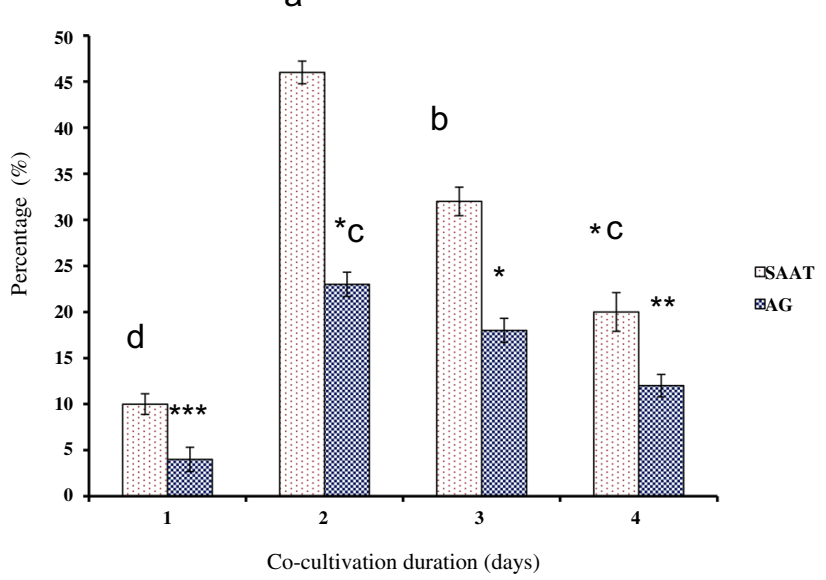

Fig. 4 Effect of co-cultivation period on transformation rate in $C$. roseus 
enhance transformation events, but bacteria incline to colonize the explant topology triggering tissue necrosis and finally death of explants (Folta et al. 2006). In contrast to previous studies, we observed that $C$. roseus did not show significant differences in the transformation rates with cocultivation for 1, 2, 3 days (Wang et al. 2012). In the present study, Agrobacterium infection was cultured for $30 \mathrm{~min}$ in MS liquid medium followed by co-cultivation for $48 \mathrm{~h}$ enhance the transformation rate $46 \%$ in SAAT as compared to $23 \%$ in conventional method (Fig. 4).

Transformed hypocotyl explants obtained from 6-dayold $C$. roseus seedlings were cultured in callus induction medium [MS salts, BAP $\left(1.0 \mathrm{mg} \mathrm{L}^{-1}\right)$, NAA $\left(0.5 \mathrm{mg} \mathrm{L}^{-1}\right)$ proline $\left(250 \mathrm{mg} \mathrm{L}^{-1}\right)$, casein hydrolysate $\left(150 \mathrm{mg} \mathrm{L}^{-1}\right)$ sucrose $(3 \% \mathrm{w} / \mathrm{v})$ and agar $(0.8 \% \mathrm{w} / \mathrm{v})]$. After induction of calli, it was transferred to shoot induction medium (SIM) with concentration of $40 \mathrm{mg} \mathrm{L}^{-1}$. No callus growth or shoot regeneration was, however, observed on the medium with either $40 \mathrm{mg} \mathrm{L}^{-1}$ or higher concentrations of kanamycin in un-transformed explants. Transformed calli were further transferred to SISM containing MS salts, BAP (4.0 $\left.\mathrm{mg} \mathrm{L}^{-1}\right)$, NAA $\left(0.05 \mathrm{mg} \mathrm{L}^{-1}\right)$ proline $\left(250 \mathrm{mg} \mathrm{L}^{-1}\right)$, casein hydrolysate $\left(150 \mathrm{mg} \mathrm{L}^{-1}\right), \quad$ kanamycin $\left(40 \mathrm{mg} \mathrm{L}^{-1}\right)$, sucrose $(3 \% \mathrm{w} / \mathrm{v})$ and agar $(0.8 \% \mathrm{w} / \mathrm{v})$ to observe the selection pressure for induction of putative transformants. After one week of callus development, most of the un-transformed calli did not produce shoots and died, but some of the transformed calli induced shoots on SISM (Fig. 2). Out of 200 explants used for transformation experiments, only 14 kanamycin-resistant shoots were induced (Table 4). This finding could be due to plant genotype, pre-culture time, co-cultivation condition, bacterial density and use of osmoprotectant and absorbent.

\section{GFP localization and molecular analyses of $C$. roseus plantlets}

In the recent past, it was significant to know the transgene localization and level of expression in different cells, GFP based study achieved this task easily in short period of time after transfection of explants have been used. Therefore, we used GFP-based construct to optimize the rate of transformation frequency and analyse the localization of GFP at the cellular level in C. roseus using confocal laser scanning microscopy (CLSM) and florescent microscopy. The results revealed by confocal microscopy showed distinct subcellular localization of GFP expressing in cells of C. roseus leaves after Agrobacterium-mediated transformation (Fig. 5). Out of 14 kanamycin-resistant plantlets were tested for GFP localization, 12 plants gave the positive signals of GFP expression in SAAT while 7 were obtained using conventional method. The differences between SAAT and conventional method may due to the
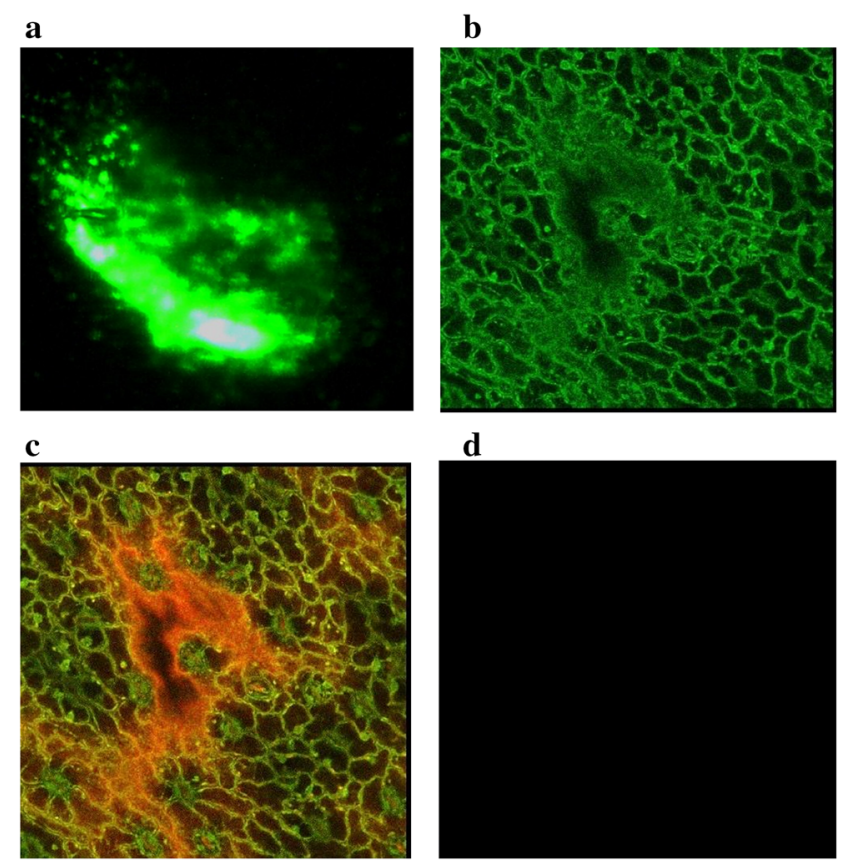

Fig. 5 Visualization of green fluorescent protein in transformed Catharanthus roseus leaf. a Fluorescent microscope view, b confocal microscopic view, c GFP expression fused with chlorophyll (red), d un-transformed leaf

M PC UT T

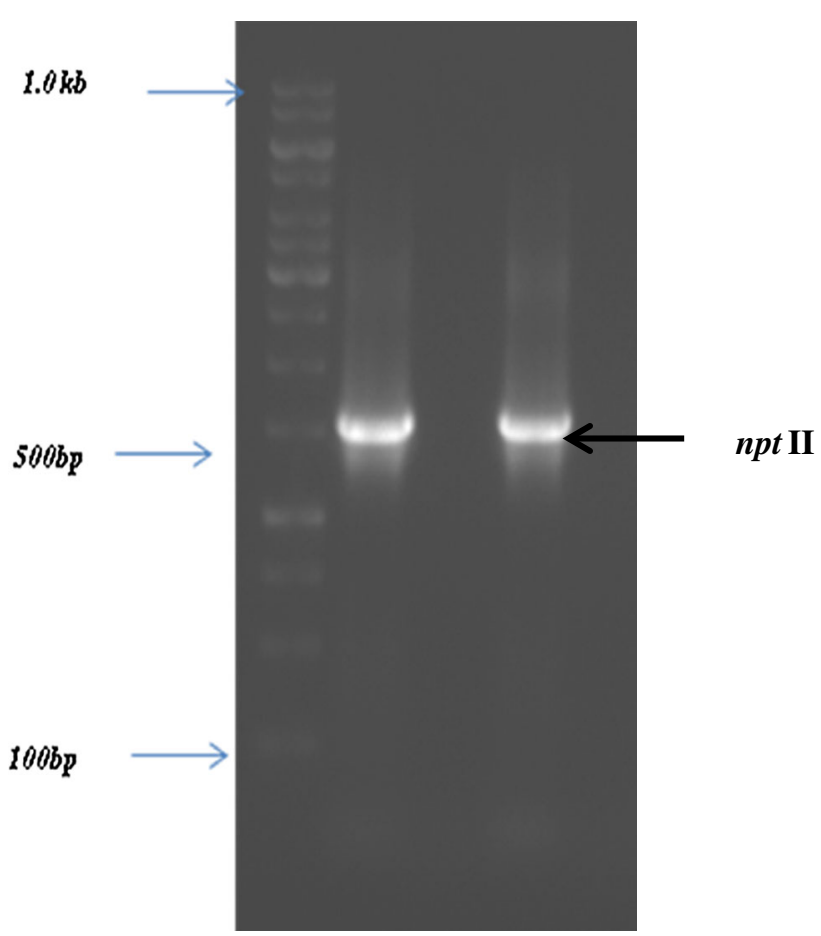

Fig. 6 PCR analysis for the presence of the nptII gene in kanamycinresistant $C$. roseus transgenic lines. Lanes: M: $1 \mathrm{~kb}$ ladder, PCpositive control of nptII from pRepGFP0029, UT-non-transgenic control plant, T-PCR positive Transformed C. roseus line 
use of sonication process to integrate the construct in $C$. roseus genome (Table 4).

Genomic DNA from GFP positive and un-transformed leaves of $C$. roseus was extracted and PCR analysis was carried out using gene-specific primers for nptII. All the GFP positive transformants showed the presence of 500 bps nptII gene as a selectable marker gene (Fig. 6). The transformation efficiency was, thus, $6.0 \%$ obtained in SAAT than $3.5 \%$ in the conventional method. Our results were also consonant with the earlier study of Wang et al. (2012). The success of high rate in production of stable transformed shoots from hypocotyl explants reported in this study is obtained by influencing some parameters like explants types, bacterial strain and co-cultivation condition.

Acknowledgements P. A. is thankful to UGC, Govt. of India, for providing Dr. D. S. Kothari post-doctoral fellowship. We are also thankful to Sara Alghonaim Research Chair, Biology Department, Prince Sattam bin Abdulaziz University, for technical support.

\section{Compliance with ethical standards}

Conflict of interest The authors state that they have no conflict of interest.

Open Access This article is distributed under the terms of the Creative Commons Attribution 4.0 International License (http:// creativecommons.org/licenses/by/4.0/), which permits unrestricted use, distribution, and reproduction in any medium, provided you give appropriate credit to the original author(s) and the source, provide a link to the Creative Commons license, and indicate if changes were made.

\section{References}

Alam P, Abdin MZ (2011) Over-expression of HMG-CoA reductase and amorpha-4,11-diene synthase genes in Artemisia апnиа L. and its influence on artemisinin content. Plant Cell Rep 30:1919-1928. doi:10.1007/s00299-011-1099-6

Alam P, Mohammad A, Ahmad MM, Khan MA, Nadeem M, Khan R, Akmal M, Ahlawat S, Abdin MZ (2014) Efficient method for Agrobacterium mediated transformation of Artemisia annual. Recent Pat Biotechnol 8:102-107

Bennici A, Caffaro L, Dameri RM et al (1988) Callus formation and plantlet regeneration from immature Triticum durum Desf. embryos. Euphytica 39:255-263

Burdyn L, Luna C, Tarracó J et al (2006) Direct shoot regeneration from leaf and internode explants of Aloysia polystachya [GRIS.] mold. (Verbenaceae). Vitr Cell Dev Biol Plant 42:235-239. doi:10.1079/IVP2006751

Chawla HS, Wenzel G (1987) Regeneration potential of callus from wheat and barley. Arch Züchtungsforsch 17:337-343

Chen FQ, Fu Y, Wang DL et al (2007) The effect of plant growth regulators and sucrose on the micropropagation and microtuberization of Dioscorea nipponica Makino. J Plant Growth Regul 26:38-45. doi:10.1007/s00344-005-0147-2

Doyle JJ, Doyle JL (1990) Isolation of plant DNA from fresh tissue. Focus 12:13-15
Facchini PJ, De Luca V (2008) Opium poppy and Madagascar periwinkle: model non-model systems to investigate alkaloid biosynthesis in plants. Plant J 54:763-784. doi:10.1111/j.1365313X.2008.03438.x

Faisal M, Anis M (2006) Thidiazuron induced high frequency axillary shoot multiplication in Psoralea corylifolia. Biol Plant 50:437-440. doi:10.1007/s10535-006-0064-7

Folta KM, Dhingra A, Howard L et al (2006) Characterization of LF9, an octoploid strawberry genotype selected for rapid regeneration and transformation. Planta 224:1058-1067. doi:10.1007/s00425006-0278-0

Hembrom ME, Martin KP, Patchathundikandi SK, Madassery J (2006) Rapid in vitro production of true-to-type plants of Pogostemon heyneanus through dedifferentiated axillary buds. Vitr Cell Dev Biol Plant 42:283-286. doi:10.1079/IVP2006757

Husaini AM (2009) Pre- and post-agroinfection strategies for efficient leaf disk transformation and regeneration of transgenic strawberry plants. Plant Cell Rep 29:97-110. doi:10.1007/s00299009-0801-4

Khan ZA, Abdin MZ, Khan JA (2015) Functional characterization of a strong bidirectional constitutive plant promoter isolated from cotton leaf curl Burewala virus. PLoS One 10:1-18. doi:10.1371/ journal.pone.0121656

Kiani BH, Suberu J, Barker GC, Mirza B (2014) Development of efficient miniprep transformation methods for Artemisia annua using Agrobacterium tumefaciens and Agrobacterium rhizogenes. Vitr Cell Dev Biol Plant 50:590-600. doi:10.1007/s11627014-9607-3

Lange BM, Wildung MR, Stauber EJ et al (2000) Probing essential oil biosynthesis and secretion by functional evaluation of expressed sequence tags from mint glandular trichomes. Proc Natl Acad Sci USA 97:2934-2939. doi:10.1073/pnas.97.6.2934

Liscombe DK, Usera AR, O'Connor SE (2010) Homolog of tocopherol $C$ methyltransferases catalyzes $N$ methylation in anticancer alkaloid biosynthesis. Proc Natl Acad Sci USA 107:18793-18798. doi:10.1073/pnas.1009003107

Liu CZ, Gao M, Guo B (2008) Plant regeneration of Erigeron breviscapus (vant.) Hand. Mazz. and its chromatographic fingerprint analysis for quality control. Plant Cell Rep 27:39-45. doi:10.1007/s00299-007-0466-9

Montoro P, Rattana W, Pujade-Renaud V et al (2003) Production of Hevea brasiliensis transgenic embryogenic callus lines by Agrobacterium tumefaciens: roles of calcium. Plant Cell Rep 21:1095-1102. doi:10.1007/s00299-003-0632-7

Morgan JA, Barney CS, Penn AH, Shanks JV (2000) Effects of buffered media upon growth and alkaloid production of Catharanthus roseus hairy roots. Appl Microbiol Biotechnol 53:262-265

Mujib A, Ali M, Isah T, Dipti (2014) Somatic embryo mediated mass production of Catharanthus roseus in culture vessel (bioreactor)—a comparative study. Saudi J Biol Sci 21:442-449. doi:10. 1016/j.sjbs.2014.05.007

Murashige T, Skoog F (1962) A revised medium for rapid growth and bioassays with tobacco tissue cultures. Physiol Plant 15:473-497

Peebles CAM, Hughes EH, Shanks JV, San KY (2009) Transcriptional response of the terpenoid indole alkaloid pathway to the overexpression of ORCA3 along with jasmonic acid elicitation of Catharanthus roseus hairy roots over time. Metab Eng 11:76-86. doi:10.1016/j.ymben.2008.09.002

Schröder G, Unterbusch E, Kaltenbach M et al (1999) Light-induced cytochrome P450-dependent enzyme in indole alkaloid biosynthesis: tabersonine 16-hydroxylase. FEBS Lett 458:97-102. doi:10.1016/S0014-5793(99)01138-2

Sivanesan I, Jeong BR (2007) Direct shoot regeneration from nodal explants of Sida cordifolia Linn. Vitr Cell Dev Biol Plant 43:436-441. doi:10.1007/s11627-007-9090-1 
Thorpe TA (2006) History of plant tissue culture. Methods Mol Biol 318:9-32. doi:10.1385/1-59259-959-1:009

van Der Heijden R, Jacobs DI, Snoeijer W et al (2004) The Catharanthus alkaloids: pharmacognosy and biotechnology. Curr Med Chem 11:607-628. doi:10.2174/0929867043455846
Wang Q, Xing S, Pan Q et al (2012) Development of efficient catharanthus roseus regeneration and transformation system using Agrobacterium tumefaciens and hypocotyls as explants. BMC Biotechnol 12:34. doi:10.1186/1472-6750-12-34 